\title{
Epidemiologic characteristics of death by burn injury from 2000 to 2009 in Colombia, South America: a population-based study
}

\author{
Norberto Navarrete ${ }^{1 *}$ and Nelcy Rodriguez ${ }^{2,3}$
}

\begin{abstract}
Background: Burns are one of the most severe traumas that an individual can suffer. The World Health Organization (WHO) affirms that injuries related to burns are a global public health problem mainly in low- and middle-income countries. The first step towards reducing any preventable injury is based on accurate information. In Colombia, the basic epidemiological characteristics of burn injuries are unknown. The objectives were establishing the causes, high-risk populations, mortality rate, and tendencies of burn deaths.
\end{abstract}

Methods: Observational, analytical, population-based study based on official death certificate occurred between 2000 and 2009. All codes of the International Classification of Diseases-10th Revision (ICD-10) related to burns were included. The mortality rates were standardized using the WHO world average age weights 2000-2025. To determine the tendency, an average annual percent change (AACP) was calculated.

Results: A total of 5448 deaths due to burns were identified; $78.4 \%$ were men. The crude and adjusted burn mortality rate was 1.270 and 1.302 per 100,000 , respectively. The AACP was $-5.25 \%$. Electrical injury caused the greatest number of deaths (49.5\%), followed by fire and lightning injuries. A total of 1197 (22.1\%) children were under 15 years old. The causes of deaths were different among age groups. $59.4 \%$ deaths occurred outside health institutions.

Conclusions: This study is a first step in identifying the main causes of death and groups with higher mortality rates. Electricity is the main cause of deaths due to burn injury. Further research is required in order to generate awareness among government and community for reducing the number of injuries and burn deaths in our country.

\section{Background}

Traumatic injuries represent one of the most important public health problems that both developing and industrialized countries face. In Colombia in the year 2009, there were 35,430 deaths due to external causes or trauma, which account for $18.0 \%$ of all deaths [1]. Burned patients present one of the most severe traumas to which an individual can be exposed and produce a significant morbidity and mortality in developed or developing countries at all ages [2].

Burns are not just a medical problem. Both the patient and the family face physical and psychological problems

\footnotetext{
* Correspondence: nnavarrete.md@gmail.com

${ }^{1}$ Burn Intensive Care Unit, Simón Bolívar Hospital, Bogotá, Colombia

Full list of author information is available at the end of the article
}

that go beyond the period of hospitalization [3-6]. The society also shares these effects in terms of disease burden, not only for the high costs of the treatment but also because fire-related burns are among the leading causes of disability-adjusted life years (DALYs) [7, 8].

Like the vast majority of traumatic injuries, burn injuries may be preventable [9-11]; epidemiological studies must be performed in order to establish special information to be provided as the basis for prevention programs, for their design and implementation. This paper presents the first general approach to the problem of burn injuries in Colombia, which may allow the effective design and implementation of prevention programs, and therefore have an impact in the reduction of the mortality rate and sequelae of patients with burns. 


\section{Methods}

During the middle of 2011, an academic project was begun to obtain epidemiological information regarding thermal injuries in our country (PREVER: Register and Evaluation of Electricity and Lightning Injuries Program), with the support of two scientific societies. We requested developing a customized process for deaths caused by burns, with codes according to the International Classification of Diseases-10th Revision (ICD-10) of the World Health Organization (WHO) (Table 1), from 1 January 2000 to 31 December 2009. Official data was collected by the National Administrative Department of Statistics (Departamento Administrativo Nacional de Estadistica$D A N E$ ) on vital statistics-death certificates. In Colombia, a death certificate must be completed after conducting the autopsy process in all accidental deaths.

We conducted an observational, descriptive, retrospective analysis. The data described has to be considered as population-based rather than hospital-based study. Data collected includes sociodemographic standard information (age, gender, area and site of death, marital status, educational level, and social security regime). Mortality rates are expressed as deaths per 100,000 people using official estimated population by DANE [1]. The rates were age-standardized using the direct method with 5-year age categories and were calculated

Table 1 International classification of disease (ICD-10) codes to burn agent

\begin{tabular}{|c|c|c|}
\hline Code & Definition & Category \\
\hline W85-W87 & Exposure to electric current & Electric \\
\hline X00-X09 & Exposure to smoke, fire, and flames & Fire \\
\hline X10 & $\begin{array}{l}\text { Contact with hot drinks, food, fats, } \\
\text { and cooking oils }\end{array}$ & Hot liquids \\
\hline$\times 11$ & Contact with hot tap water & Hot liquids \\
\hline$X 12$ & Contact with other hot fluids & Hot liquids \\
\hline $\mathrm{X} 13$ & Contact with steam and hot vapors & Hot gases \\
\hline X14 & Contact with hot air and gases & Hot gases \\
\hline$\times 15$ & Contact with hot household appliances & Hot solid \\
\hline X16 & $\begin{array}{l}\text { Contact with hot heating appliances, } \\
\text { radiators, and pipes }\end{array}$ & Hot solid \\
\hline$\times 17$ & $\begin{array}{l}\text { Contact with hot engines, machinery, } \\
\text { and tools }\end{array}$ & Hot solid \\
\hline X18 & Contact with other hot metals & Hot solid \\
\hline X19 & $\begin{array}{l}\text { Contact with other and unspecified } \\
\text { heat and hot substances }\end{array}$ & Unspecified \\
\hline X33 & Victim of lightning & Electric \\
\hline X76 & $\begin{array}{l}\text { Intentional self-harm by smoke, fire, } \\
\text { and flames }\end{array}$ & Self-harm \\
\hline$\times 77$ & $\begin{array}{l}\text { Intentional self-harm by steam, } \\
\text { hot vapors, and hot objects }\end{array}$ & Self-harm \\
\hline
\end{tabular}

using the WHO world average age weights 2000-2025. We performed an average annual percent change (AAPC), to determine the tendency of the adjusted mortality rate.

All statistical calculations were done using the program Stata, 11th version, educational license (StataCorp, College Station, TX) except AAPC, which was done on Microsoft Excel (2010).

In Colombia, resolution 8430 of 1993 defines these types of studies as those with "no risk" since they do not identify the people who are object of the study or treat sensitive issues. Also, no physiological variables are manipulated or patients accessed directly. Thus, no previous evaluation from the ethics committee was requested for using this database.

\section{Results}

In total, 5448 deaths due to burns were identified from the death certificates; 4270 (78.4\%) were men; the male to female ratio was 3.6:1; age was unknown for 31 of the deaths. The age range was from 3 days to 95 years, median was 29 years (interquartile range (IQR) 17-43). Age distribution is shown in Fig. 1. By gender, males had a mean age of 31.8 years (IQR 19-43) and females a mean age of 28.6 (IQR 4-46). In women of childbearing age, there were 19 (3.4\%) cases of pregnancy who died from burns. At the time of signing the death certificate, it was unknown whether $249(44.8 \%)$ of the women from this group were pregnant or not. Although in Colombia, people under 18 are considered underage, hospitals usually regard children for the pediatric population until they are 14 years old. A total of 1197 children under 15 years old died (22.1\%) with median age of 3 years (IQR 1-8); 735 (61.4\%) were men. This gives

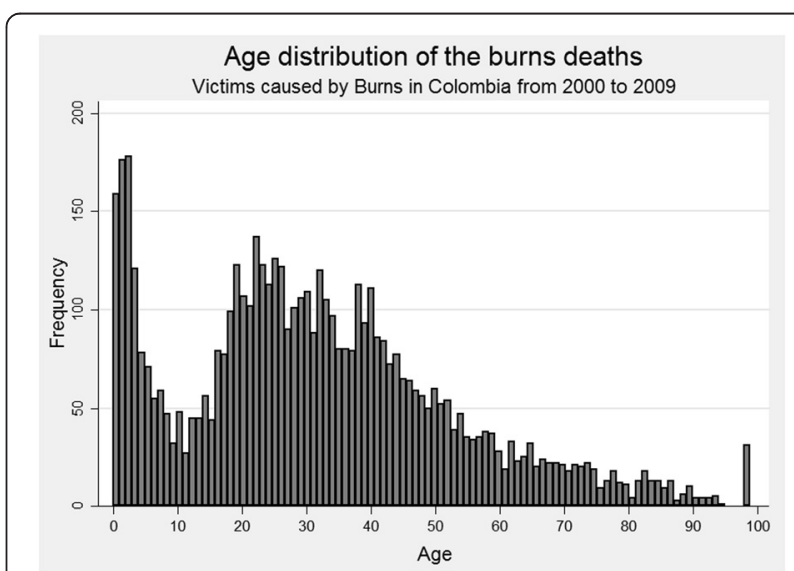

Fig. 1 Age distribution of cases in Colombia fatalities by burns during the years 2000-2009. The bar at age 99 is for patients with indeterminate age during the processing of the death certificate 
Table 2 Crude and standardized rate of fatal burns in Colombia in the years 2000-2009

\begin{tabular}{llllll}
\hline Year & Deaths & Estimated population & Crude mortality rate/100,000 & Adjusted mortality rate/100,000 & Confidence interval \\
\hline 2000 & 560 & $40,295,563$ & 1.390 & 1.400 & {$[1.438-1.463]$} \\
2001 & 591 & $40,813,541$ & 1.448 & 1.455 & {$[1.487-1.512]$} \\
2002 & 559 & $41,328,824$ & 1.353 & 1.362 & 1.474 \\
2003 & 617 & $41,848,959$ & 1.474 & $1.386-1.410]$ \\
2004 & 554 & $42,368,489$ & 1.308 & 1.317 & {$[1.503-1.528]$} \\
2005 & 558 & $42,888,592$ & 1.301 & 1.308 & {$[1.329-1.352]$} \\
2006 & 559 & $43,405,956$ & 1.288 & 1.292 & {$[1.305-1.327]$} \\
2007 & 495 & $43,926,929$ & 1.127 & 1.138 & {$[1.306-1.328]$} \\
2008 & 488 & $44,451,147$ & 1.098 & 1.102 & {$[1.153-1.174]$} \\
2009 & 436 & $44,978,832$ & 0.969 & 0.978 & {$[1.114-1.134]$} \\
Total & 5417 & $42,630,683$ & 1.270 & 1.302 & {$[0.969-0.987]$} \\
\hline
\end{tabular}

a male to female ratio of $1.6: 1$ among the pediatric population.

The burn mortality rate in Colombia is 1.270 per 100,000 per year during the study period (Table 2). The adjusted mortality rate was 1.302 per 100,000 per year. There was a progressive decline in mortality from burns in the course of the years of the study. The average percent mortality change for burn deaths was $-5.25 \%$. Populations with higher mortality rates are those under 5 years and over 65 years old (Fig. 2). The mortality rate for male was 2.029 and for females 0.546 .

Regarding the causal agent, it was found that electricity is the leading cause of deaths by burns in our country $(49.5 \%)$, followed by fire $(28.5 \%)$ and lightning

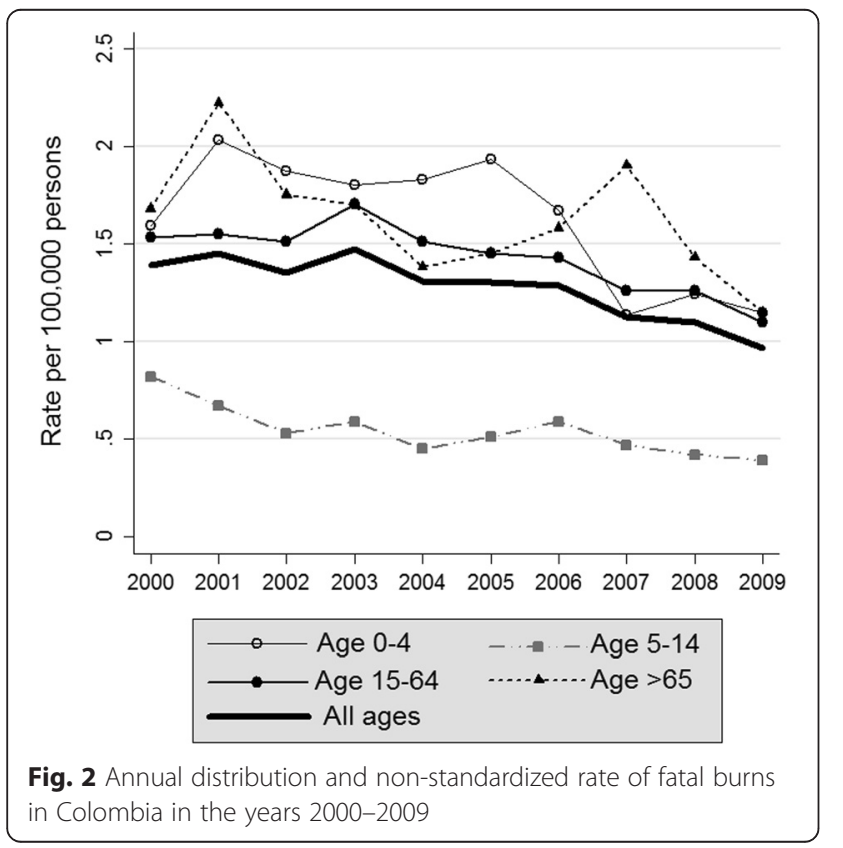

injuries $(13.9 \%)$. The two electrical mechanisms (natural and human) were responsible for 4247 (78.0 \%) of deaths during the study period (Table 3). However, there are differences according to the age. In the underage, the most common cause is injury due to fire (44.1\%), followed by electricity $(29.9 \%)$ and hot liquids $(17.5 \%)$. In adults, the most common cause is electricity (55.1\%), followed by fire $(24.0 \%)$ and lightning (15.8 \%). Given this age difference, we present the frequency of burn agents by age group (Table 4) and mortality rates by cause of burns and age groups (Fig. 3).

A percentage of 50.6 of those deceased (2759) did not receive medical attention during the process that produced their death. Regarding the site of death, 2093 (38.4\%) deaths happened in hospitals, clinics, or village health centers, 3238 (59.4\%) were outside health institutions, and there was no information on 117 (2.2\%). There are a significant number of deaths outside health institutions. As for the 3238 deaths outside hospitals, the main cause is electrical injury. Human and natural electricity (lightning) are the cause of $73.5 \%$ of the deaths in households, $92.5 \%$ of the deaths in the workplace, and

Table 3 Mechanisms of injury in burns fatalities in Colombia

\begin{tabular}{lll}
\hline Burn agent & Deaths & $\%$ \\
\hline Electric & 2695 & 49.5 \\
Lightning & 757 & 13.9 \\
Fire & 1552 & 28.5 \\
Hot liquids & 283 & 5.2 \\
Hot gases & 23 & 0.4 \\
Hot solid & 20 & 0.4 \\
Unspecified & 36 & 0.7 \\
Suicides & 82 & 1.5 \\
\hline
\end{tabular}


Table 4 Frequency and percentage of burn agents by age group (31 patients with indeterminate age)

\begin{tabular}{|c|c|c|c|c|c|c|c|c|}
\hline \multirow[t]{2}{*}{ Age group } & \multicolumn{2}{|c|}{$0-5$ years } & \multicolumn{2}{|c|}{$6-14$ years } & \multicolumn{2}{|c|}{ 15-64 years } & \multicolumn{2}{|c|}{$>65$ years } \\
\hline & Deaths & $\%$ & Deaths & $\%$ & Deaths & $\%$ & Deaths & $\%$ \\
\hline Electric & 180 & 23.0 & 178 & 43.0 & 2225 & 58.6 & 98 & 23.1 \\
\hline Lightning & 17 & 2.2 & 69 & 16.7 & 624 & 16.5 & 43 & 10.1 \\
\hline Fire & 380 & 48.5 & 148 & 35.8 & 773 & 20.4 & 239 & 56.4 \\
\hline Hot liquids & 193 & 24.6 & 17 & 4.1 & 54 & 1.4 & 18 & 4.3 \\
\hline Hot gases & 3 & 0.4 & 1 & 0.2 & 15 & 0.4 & 4 & 0.9 \\
\hline Hot solid & 3 & 0.4 & 1 & 0.2 & 13 & 0.3 & 3 & 0.7 \\
\hline Unspecified & 7 & 0.9 & 0 & 0.0 & 20 & 0.5 & 9 & 2.1 \\
\hline Suicides & 0 & 0.0 & 0 & 0.0 & 72 & 1.9 & 10 & 2.4 \\
\hline Total & 783 & 100.0 & 414 & 100.0 & 3796 & 100.0 & 424 & 100.0 \\
\hline
\end{tabular}

$93 \%$ on public roads. We present a description of the site of death according to the cause (Table 5).

In regard to the place of death, 3703 deaths $(68.0 \%)$ occurred in head municipalities, 441 (8.1 \%) died in townships or small villages and jurisdictions, and 1264
(23.2 \%) died in dispersed rural areas. There was no information on 40 certificates $(0.7 \%)$. The mortality rates were higher in rural area (1.55 per 100,000 per year) than the urban areas (1.17 per 100,000 per year). We obtained the number of deaths from counties and mortality

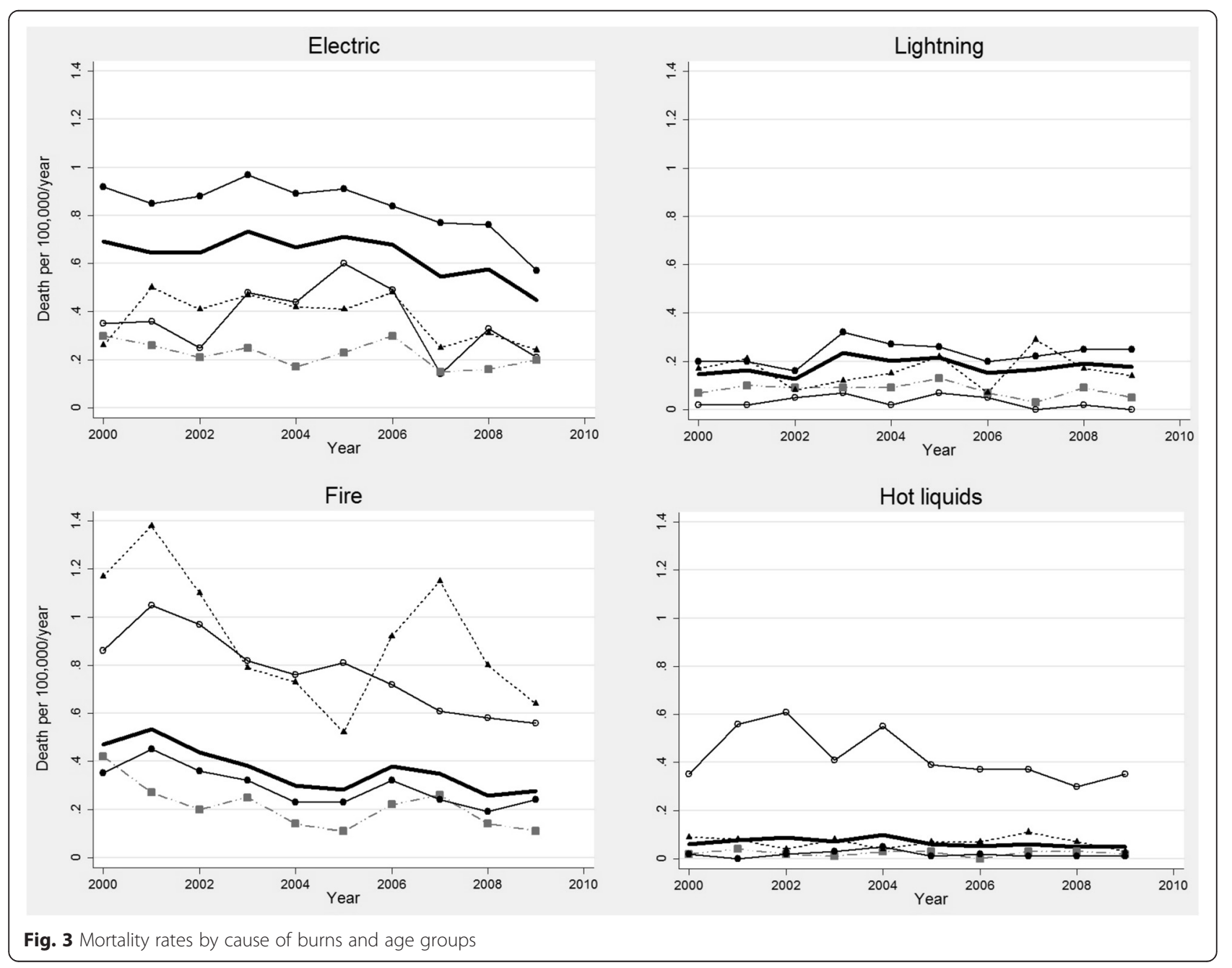


Table 5 Frequency and percentage of burn agent according to the site of death (117 patients with indeterminate or unknown cause)

\begin{tabular}{|c|c|c|c|c|c|c|c|c|c|c|c|c|}
\hline \multirow{2}{*}{$\begin{array}{l}\text { SITE } \\
\text { Cause }\end{array}$} & \multicolumn{2}{|c|}{ Hospital or clinics } & \multicolumn{2}{|c|}{ Township or village health center } & \multicolumn{2}{|l|}{ Home } & \multicolumn{2}{|c|}{ Place working } & \multicolumn{2}{|c|}{ Public road } & \multicolumn{2}{|l|}{ Others } \\
\hline & Deaths & $\%$ & Deaths & $\%$ & Deaths & $\%$ & Deaths & $\%$ & Deaths & $\%$ & Deaths & $\%$ \\
\hline Electric & 551 & 26.8 & 30 & 73.2 & 723 & 53.6 & 452 & 69.2 & 553 & 79.0 & 313 & 58.3 \\
\hline Lightning & 35 & 1.7 & 5 & 12.2 & 268 & 19.9 & 152 & 23.2 & 98 & 14.0 & 175 & 32.6 \\
\hline Fire & 1069 & 52.1 & 6 & 14.6 & 339 & 25.1 & 45 & 6.9 & 36 & 5.1 & 42 & 7.8 \\
\hline Hot liquids & 271 & 13.2 & 0 & 0.0 & 2 & 0.2 & 0 & 0.0 & 6 & 0.9 & 2 & 0.4 \\
\hline Hot gases & 19 & 0.9 & 0 & 0.0 & 1 & 0.1 & 1 & 0.2 & 0 & 0.0 & 2 & 0.4 \\
\hline Hot solid & 15 & 0.7 & 0 & 0.0 & 3 & 0.2 & 0 & 0.0 & 0 & 0.0 & 0 & 0.0 \\
\hline Unspecified & 30 & 1.5 & 0 & 0.0 & 1 & 0.1 & 1 & 0.2 & 3 & 0.4 & 0 & 0.0 \\
\hline Suicides & 62 & 3.0 & 0 & 0.0 & 11 & 0.8 & 2 & 0.3 & 4 & 0.6 & 3 & 0.5 \\
\hline Total & 2052 & 100.0 & 41 & 100.0 & 1348 & 100.0 & 653 & 100.0 & 700 & 100.0 & 537 & 100.0 \\
\hline
\end{tabular}

rates were generated (Table 6). A political map was made by those counties (departments) indicating death rates in different colors (Fig. 4).

\section{Discussion}

The WHO estimates that 195,227 people died in fires in 2008 across the world; the great majority happened in low-income and middle-income countries with a global mortality rate amounting to 2.9 per 100,000 per year [12]. The mortality rate in Colombia $(1.28$ per 100,000$)$ is low compared to the global mortality rate and it is very similar to that of other countries such as Korea (1.3 per 100.000 in 2001) and the USA (1.09 per 100,000 in 2007) $[13,14]$ but far higher than that of Mexico $(0.72$ per 100,000 in 2007) [15]; though, our mortality rate has also been declining from 1.400 to 0.978 (year 2000 to 2009 , respectively) as in other countries [15-18].

However, there is a difference with the data from international organizations. According to the WHO, Colombia has a burn mortality rate of 0.44 per 100,000 for 2008 similar to that of countries like Venezuela ( 0.43 per 100,000), Panama (0.29 per 100,000), Mexico (0.63 per 100,000), and Bolivia (0.38 per 100,000). According to this WHO data, 7752 deaths occurred in the Americas with a mortality rate of 0.85 deaths per 100,000 [12], which was well below that of Europe (2.3 per 100,000), Africa (4.9 per 100,000), and East and South Asia (4.8 per $100,000)$. Is our country and our region doing that well? This difference may have an explanation. Code U153 (GBD code) titled Unintentional injuries: Fires, used for the WHO reports, only includes the ICD-10 codes (X00-X09). It does not include codes for hot liquids (X10-X12), hot gases (X13, X14), hot solid (X15-X19), or electrical injuries (W85-W87) [19]. With electrical burns as our leading cause of death, the mortality rate in our study is 2.5 -folds higher than that reported by the WHO. With the inclusion of other causes of burns, official mortality rates can be raised not only in our country but in countries with similar characteristics of development, showing that the problem is underestimated.

The results of this epidemiological study show male predominance of burns and compromise most productive ages. These results are consistent with several reports from other populations. It was observed that scalds are significantly more frequent in less than 5year-old age group when compared with other causes of burns [18, 20-22]. Fire is a common cause of burns in children under 5 years old and men over 65 years old. Electricity affects mainly young workers so it is not surprising that there are populations with higher mortality rate than those under 5 years and over 65 years since the fatality rate in these populations is much higher.

In Colombia, in our experience, the higher frequency of electrical accidents is by accidental contact with power lines that pass very close to the houses, and they occurred usually, during local housing arrangement; in a few other cases, it is due to the illegal manipulation of electrical lines to obtain the wires and then sell the copper. Electricity can cause instant death even if the accident occurs at home with low voltage. Electricity generates cardiac arrhythmias, asystole, or prolonged respiratory arrest, which are fatal if resuscitation is not performed immediately. The vast majority die before being admitted to a medical institution [23-25].

It is interesting and surprising that lightning injuries are the third leading cause of death from burns. However, Colombia is reported as one of the countries with higher density of lightning in the world, probably because of its location relative to the equator in the intertropical confluence zone, the topographic variation, and its mountain ranges [26]. This can be explained by the high agricultural activity our country has; a quarter of our population live in remote rural areas, and there is lack of information on risk assessment and prevention. 
Table 6 Number of deaths and annual mortality rate from burns by county (department) of Colombia

\begin{tabular}{|c|c|c|c|c|}
\hline Code & Department & Deaths & $\begin{array}{l}\text { Average } \\
\text { population }\end{array}$ & $\begin{array}{l}\text { Annual death } \\
\text { rate/100,000 }\end{array}$ \\
\hline 05 & Antioquia & 696 & $5,643,511$ & 1.23 \\
\hline 08 & Atlántico & 402 & $2,151,045$ & 1.87 \\
\hline 11 & Bogotá, D.C. & 564 & $6,787,079$ & 0.83 \\
\hline 13 & Bolívar & 277 & $1,870,660$ & 1.48 \\
\hline 15 & Boyacá & 184 & $1,253,671$ & 1.47 \\
\hline 17 & Caldas & 162 & 967,591 & 1.67 \\
\hline 18 & Caquetá & 59 & 418,052 & 1.41 \\
\hline 19 & Cauca & 184 & $1,263,858$ & 1.46 \\
\hline 20 & Cesar & 152 & 897,334 & 1.69 \\
\hline 23 & Córdoba & 184 & $1,457,229$ & 1.26 \\
\hline 25 & Cundinamarca & 235 & $2,260,293$ & 1.04 \\
\hline 27 & Chocó & 52 & 451,965 & 1.15 \\
\hline 41 & Huila & 93 & $1,004,140$ & 0.93 \\
\hline 44 & La Guajira & 77 & 667,684 & 1.15 \\
\hline 47 & Magdalena & 204 & $1,145,230$ & 1.78 \\
\hline 50 & Meta & 87 & 774,750 & 1.12 \\
\hline 52 & Nariño & 174 & $1,531,949$ & 1.14 \\
\hline 54 & Norte de Santander & 285 & $1,238,465$ & 2.30 \\
\hline 63 & Quindío & 29 & 532,965 & 0.54 \\
\hline 66 & Risaralda & 96 & 894,525 & 1.07 \\
\hline 68 & Santander & 336 & $1,952,806$ & 1.72 \\
\hline 70 & Sucre & 87 & 768,273 & 1.13 \\
\hline 73 & Tolima & 136 & $1,362,424$ & 1.00 \\
\hline 76 & Valle del Cauca & 570 & $4,139,615$ & 1.38 \\
\hline 81 & Arauca & 36 & 231,074 & 1.56 \\
\hline 85 & Casanare & 26 & 292,197 & 0.89 \\
\hline 86 & Putumayo & 24 & 308,638 & 0.78 \\
\hline 88 & $\begin{array}{l}\text { Archipelago of San } \\
\text { Andrés }\end{array}$ & 9 & 70,237 & 1.28 \\
\hline 91 & Amazonas & 5 & 67,277 & 0.74 \\
\hline 94 & Guainía & 1 & 34,922 & 0.29 \\
\hline 95 & Guaviare & 11 & 94,866 & 1.16 \\
\hline 97 & Vaupés & 5 & 39,033 & 1.28 \\
\hline \multirow[t]{2}{*}{99} & Vichada & 6 & 55,188 & 1.09 \\
\hline & National total & 5448 & $42,628,541$ & 1.28 \\
\hline
\end{tabular}

There are other distinctive features of our burn mortality such as death at the scene without medical attention. Nearly half of those, who died from burns, died without getting pre-hospital medical care by trained personnel, relatives, or the community. This can be explained by two findings from our own study. First, almost all the people who suffer accidents in townships, villages, and dispersed rural areas die without medical care. Colombia is a country in northern South America; it has been estimated that by 2013, about a quarter of the population will be living outside urban areas. Colombia has a vast territory of $1,141,748 \mathrm{~km}^{2}$ which correspond to the mainland. It presents great topographic difficulty since there are three ridges which are the northern termination of the Andes. Secondly, of the accidents that occur in urban areas, a one third (32.0\%) is produced by electricity.

A limitation in our study is the difference between variables and categories during the years of the study, mainly after the implementation of electronic death certificates in 2008. At that time, new important information was added. It was impossible to determine variables, such as social security, education or marital status, or to identify whether the burn accident was related to the job. Only in the last 2 years of the study with the electronic format, the recording of deaths related to work, was included. Out of the 812 patients with the possibility of working, including children population, 144 had injuries related to the job $(17.7 \%)$. There is no such data for almost half of the cases (45.1\%). Another limitation is that there is very little availability of population-based studies to compare our findings with. Institution-based studies typically relate to the local population, the percentage of referrals from remote areas, the availability of hospital beds, the time from the accident to hospitalization, and pre-hospital fatality.

\section{Recommendations}

Thus, the recommendations based on our results are as follow:

- To identify stakeholders and broader collaborative groups to work on prevention of burns;

- To create a national burn repository for epidemiologic and clinical data;

- To obtain data regarding the incidence of thermal injuries, the risk factors associated with burns in our community, and lethality;

- To generate prevention policies mainly in populations and areas of greatest risk (children, elderly, electrical safety);

- To implement multidisciplinary interventions for risk mitigation by community staff, primarily on the basic knowledge regarding first aid and resuscitation.

\section{Conclusions}

Burn trauma is preventable in many cases. The first step towards the development of interventions for injury prevention is surveillance and identification of the risk factors. This is the first population-based burn death study in Colombia. But deaths are only the tip of the iceberg 


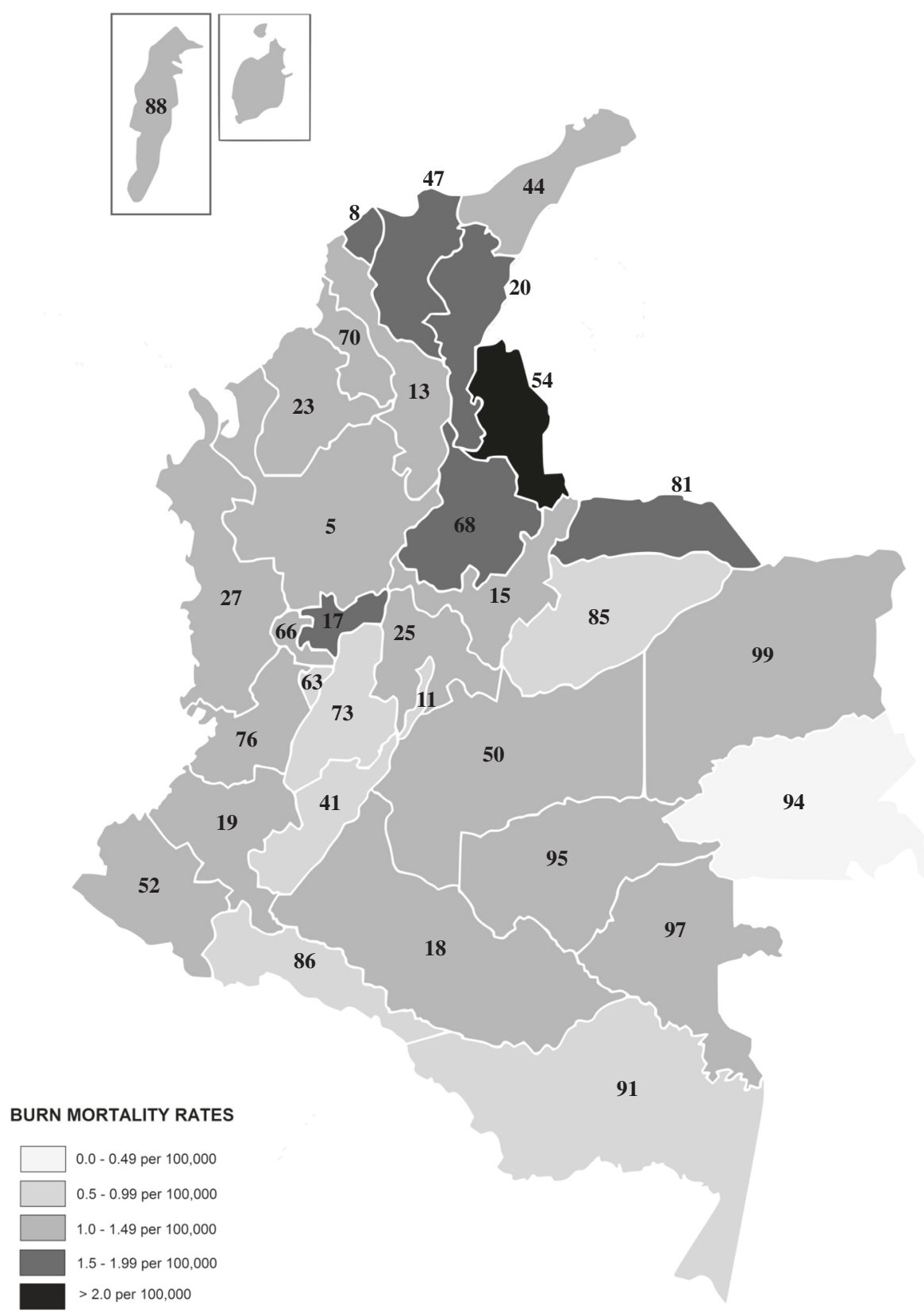

Fig. 4 Topographic distribution of mortality rates of burns by departments in Colombia 2000 to 2009

and the number of non-fatal injuries per year, morbidity, and lethality in our country is unknown.

Our study identifies risk at all ages for different reasons. Population groups with higher risk are those under 5 years and over 65 years old. The mortality rate tended to decrease during the length of the study and was higher in rural area than the urban areas. Electricity is the principal cause of burn deaths in Colombia, followed by fire and lightning and the deaths occurred mainly outside health institutions. Children under 5 years are affected principally due to fire and scalds.

A few specific recommendations can be given based on these epidemiologic features that will allow for the design of prevention strategies for this type of injury, focused mainly on electrical injuries in young people, fire burn injuries in children, and also first aid measures mainly regarding cardiopulmonary resuscitation. 


\section{Competing interests}

The authors declare that they have no competing interests.

\section{Authors' contributions}

NN participated in the design of the study and data collection. NN and NR were responsible for data analysis. NN drafted the paper and discussed with NR to finalize the manuscript. Both authors read and approved the final manuscript.

\section{Author details}

${ }^{1}$ Burn Intensive Care Unit, Simón Bolívar Hospital, Bogotá, Colombia. ${ }^{2}$ Clinical Epidemiology and Biostatistics Department, Javeriana University, Bogotá, Colombia. ${ }^{3}$ Department of Statistics, National University of Colombia, Bogotá, Colombia.

\section{Received: 25 November 2015 Accepted: 9 March 2016} Published online: 16 March 2016

\section{References}

1. DANE: Departamento Administrativo Nacional de Estadistica-DANE. In demographic — vital statistics—deaths results—non fetal. Available at: http://www.dane.gov.co. Accessed 2 Feb 2012

2. Mashreky SR, Rahman A, Chowdhury SM, Giashuddin S, Svanström L, Khan TF, et al. Burn injury: economic and social impact on a family. Public Health. 2008; 122(12):1418-24.

3. Pruitt Jr BA, Mason Jr AD. Epidemiological, demographic and outcome characteristics of burn injury. In: Herndon DN, editor. Total burn care. 1st ed. London: WB Saunders Company; 1996. p. 14-32.

4. Kimmo T, Jyrki $V$, Sirpa AS. Health status after recovery from burn injury. Burns. 1998;24(4):293-8.

5. Blakeney P, Meyer 3rd W, Robert R, Desai M, Wolf S, Herndon D. Long-term psychosocial adaptation of children who survive burns involving $80 \%$ or greater total body surface area. J Trauma. 1998;44(4):625-32.

6. Fauerbach JA, Lezotte D, Hills RA, Cromes GF, Kowalske K, de Lateur BJ, et al. Burden of burn: a norm-based inquiry into the influence of burn size and distress on recovery of physical and psychosocial function. J Burn Care Rehabil. 2005;26(1):21-32

7. World Health Organization (WHO). In media centre. Fact sheet $N^{\circ} 365$. Burns. Available at: http://www.who.int/mediacentre/factsheets/fs365/en/index html. Accessed 2 Feb 2012

8. Hyder AA, Sugerman DE, Puvanachandra P, Razzak J, El-Sayed H, Isaza A, et al. Global childhood unintentional injury surveillance in four cities in developing countries: a pilot study. Bull World Health Organ. 2009;87(5):345-52.

9. Clark DE, Katz MS, Campbell SM. Decreasing mortality and morbidity rates after the institution of a statewide burn program. J Burn Care Rehabil. 1992; 13(2 Pt 1):261-70

10. Edelman LS. Social and economic factors associated with the risk of burn injury. Burns. 2007;33(8):958-65. Epub 2007 Sep 14. Review.

11. Ghosh A, Bharat R. Domestic burns prevention and first aid awareness in and around Jamshedpur, India: strategies and impact. Burns. 2000;26(7):605-8

12. World Health Organization (WHO). Global Burden of disease. Health Statistics and Health Information Systems. Cause-specific mortality: regional estimates for 2008. WHO 2008. Available at: http://www.who. int/healthinfo/global_burden_disease/estimates_regional_2004_2008/en/ Accessed 14 March 2013.

13. Han TH, Kim JH, Yang MS, Han KW, Han SH, Jung JA, et al. A retrospective analysis of 19,157 burns patients: 18-year experience from Hallym Burn Center in Seoul, Korea. Burns. 2005;31(4):465-70.

14. National Center for Injury Prevention and Control: webbased injury and statistics query and reporting system (WISQARSTM) injury mortality reports, 1999-2007 Atlanta, GA: Centers for Disease Control; 2009, Available at: http://webappa.cdc.gov/sasweb/ncipc/mortrate9.html Accessed 6 Feb 2013.

15. Orozco-Valerio MJ, Miranda-Altamirano RA, Mendez AC, Celis A. Tendencia de mortalidad por quemaduras en Mexico, 1979-2009. Gac Med Mex. 2012. 148(4):349-57

16. Danilla Enei S, Pastén Rojas J, Fasce Pineda G, Díaz Tapia V, Iruretagoyena BM. Mortality trends from burn injuries in Chile: 1954-1999. Burns. 2004;30(4):348-56.

17. Blaisdell LL, Chace R, Hallagan LD, Clark DE. A half-century of burn epidemiology and burn care in a rural state. J Burn Care Res. 2012;33(3):347-53.
18. Duke J, Wood F, Semmens J, Spilsbury K, Edgar DW, Hendrie D, et al. A 26-year population-based study of burn injury hospital admissions in Western Australia. J Burn Care Res. 2011;32(3):379-86.

19. Word Health Organization (WHO). Global Burden of Disease (GBD) Study 2000-2002: definitions of cause categories in terms of International Classification of Disease (ICD) codes. Available at: URL:http://www.who.int/ healthinfo/statistics/gbdestimatescauselist.pdf. Accessed 13 March 2013.

20. American Burn Association (ABA). 2012 National Burn Repository. Report of data from 2002-2011. Available at: http://www.ameriburn.org/ 2012NBRAnnualReport.pdf Accessed 13 March 2013.

21. Teo Al, Van As AB, Cooper J. A comparison of the epidemiology of paediatric burns in Scotland and South Africa. Burns. 2012;38(6):802-6.

22. Brusselaers N, Monstrey S, Vogelaers D, Hoste E, Blot S. Severe burn injury in Europe: a systematic review of the incidence, etiology, morbidity, and mortality. Crit Care. 2010;14(5):R188. Review.

23. Shaha KK, Joe AE. Electrocution-related mortality: a retrospective review of 118 deaths in Coimbatore, India, between January 2002 and December 2006. Med Sci Law. 2010;50(2):72-4.

24. Fatovich DM. Electrocution in Western Australia, 1976-1990. Med J Aust. 1992:157(11-12):762-4

25. Bailey B, Forget S, Gaudreault P. Prevalence of potential risk factors in victims of electrocution. Forensic Sci Int. 2001:123(1):58-62.

26. Cooper MA, Andrews CJ, Holle RL. Lightning injuries. In: Auerbach PS, editor. Wilderness Medicine. Philadelphia: Mosby Elsevier; 2007. p. 67-108.

\section{Submit your next manuscript to BioMed Central and we will help you at every step:}

- We accept pre-submission inquiries

- Our selector tool helps you to find the most relevant journal

- We provide round the clock customer support

- Convenient online submission

- Thorough peer review

- Inclusion in PubMed and all major indexing services

- Maximum visibility for your research

Submit your manuscript at www.biomedcentral.com/submit 